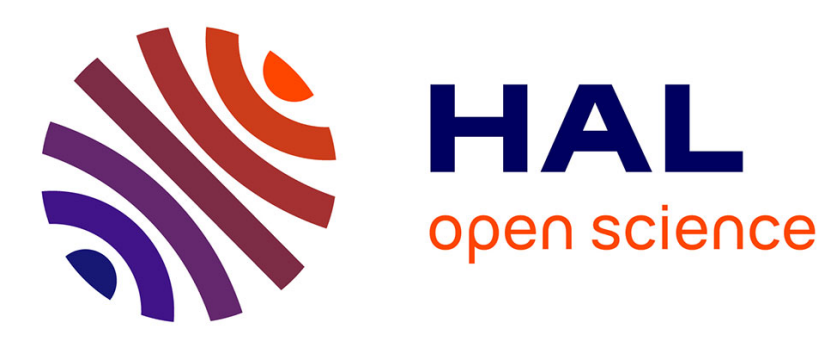

\title{
Advanced characterization unravels the structure and reactivity of wood-based chars
}

Sarah Berhanu, Maxime Hervy, Elsa Weiss-Hortala, Henry Proudhon, Marie-Hélène Berger, Anthony Chesnaud, Matthieu Faessel, Andrew D. King, Doan Pham Minh, Audrey Villot, et al.

\section{To cite this version:}

Sarah Berhanu, Maxime Hervy, Elsa Weiss-Hortala, Henry Proudhon, Marie-Hélène Berger, et al.. Advanced characterization unravels the structure and reactivity of wood-based chars. Journal of Analytical and Applied Pyrolysis, 2018, 130, p.79-89. 10.1016/j.jaap.2018.01.024 . hal-01700193

\section{HAL Id: hal-01700193 \\ https://hal.science/hal-01700193}

Submitted on 12 Oct 2018

HAL is a multi-disciplinary open access archive for the deposit and dissemination of scientific research documents, whether they are published or not. The documents may come from teaching and research institutions in France or abroad, or from public or private research centers.
L'archive ouverte pluridisciplinaire HAL, est destinée au dépôt et à la diffusion de documents scientifiques de niveau recherche, publiés ou non, émanant des établissements d'enseignement et de recherche français ou étrangers, des laboratoires publics ou privés. 


\title{
Advanced characterization unravels the structure and reactivity of wood- based chars
}

\author{
Sarah Berhanu ${ }^{\mathrm{a}}$, Maxime Hervy ${ }^{\mathrm{b}, \mathrm{c}}$, Elsa Weiss-Hortala ${ }^{\mathrm{c}, *}$, Henry Proudhon $^{\mathrm{a}}$, \\ Marie-Hélène Berger ${ }^{\mathrm{a}}$, Anthony Chesnaud ${ }^{\mathrm{a}}$, Matthieu Faessel ${ }^{\mathrm{d}}$, Andrew King ${ }^{\mathrm{e}}$, Doan Pham Minh ${ }^{\mathrm{c}}$, \\ Audrey Villot ${ }^{\mathrm{b}}$, Claire Gérente ${ }^{\mathrm{b}}$, Alain Thorel ${ }^{\mathrm{a}}$, Laurence Le Coq ${ }^{\mathrm{b}}$, Ange Nzihou ${ }^{\mathrm{c}}$ \\ a MINES ParisTech, PSL Research University, MAT - Centre des matériaux, CNRS UMR 7633, BP 87-1003 Evry, France \\ ${ }^{\mathrm{b}}$ IMT Atlantique, GEPEA, UBL, F-44307 Nantes, France \\ ${ }^{\mathrm{c}}$ Université de Toulouse, Mines Albi, UMR CNRS 5302, Centre RAPSODEE, Campus Jarlard, 81013 Albi Cedex 09, France \\ d MINES ParisTech, PSL Research University, CMM - Centre de morphologie mathématique, 35 rue St Honoré, 77300 Fontainebleau, France \\ e Synchrotron SOLEIL, L'Orme des Merisiers, Saint-Aubin, BP 48, 91192 Gif sur Yvette, France
}

\section{A B S T R A C T}

This study aims at understanding the structural changes occurring in the carbonaceous matrix of wood-based chars during their thermal conversion. Although chars are routinely characterized by porosity measurements or scanning electron microscopy, the composition and structure of the carbonaceous matrix is often not investigated. Here, advanced characterization using X-ray synchrotron microtomography, transmission electron microscopy, Raman spectroscopy and X-ray diffraction provided a precise description of the char properties, allowing for an accurate discussion of their catalytic properties. Two chars were produced by slow pyrolysis of wood waste $\left(400\right.$ and $\left.700{ }^{\circ} \mathrm{C}\right)$ and a third one was fabricated by activation under steam at $850{ }^{\circ} \mathrm{C}$ of the char obtained at $700{ }^{\circ} \mathrm{C}$. The results show that the pyrolysis temperature and the activation performed did not affect the macrostructure of the chars and that the pores were interconnected at the macroscopic scale. However, at $700{ }^{\circ} \mathrm{C}$, the micro- and nanostructures were modified: short-range organized graphene fringes were observed. The activated char showed a homogeneous microstructure similar to that of its precursor. Besides, the ratio of graphene-like structures, the local organization of graphene sheets, and the imperfections in graphene-like sheets were clearly improved by the post-treatment. To our knowledge, this is the first time that such an approach, combining various tools, is applied for the study of pyrolysis chars.

\section{Keywords:}

Wood char

Structural characterization

Electron microscopy

Microtomography

Raman spectroscopy

X-ray diffraction

\section{Introduction}

Nowadays much research is conducted to tackle the rarefaction of petroleum-based resources. Biomass and waste materials engineering is thus investigated to take into account environmental considerations. Biochars appear to be promising materials for many applications such as soil amendment, fuel, sorbent, support for catalyst, catalyst, electrochemistry, water treatment, gas cleaning, additives in anaerobic digestion, etc. [1-9]. Among these possible outcomes, energy applications, where biochar acts as a catalyst, are of great interest [10]. For instance, syngas $\left(\mathrm{CO}+\mathrm{H}_{2}\right)$ can be produced and further converted into fuel in the Fischer-Tropsch synthesis by pyro-gasification of biomass and residues. However, the development of this process is industrially limited because of by-product generation and the costly step of syngas purification $[11,12]$. In this context, some research projects focus on the direct use of chars resulting from pyro-gasification as a catalyst for hydrocarbon cracking to upgrade the syngas yield and its quality [13-22].

A better understanding of biochar structure and its evolution depending on the fabrication process is therefore required to tailor and optimize biochar properties depending on the targeted application. In the above example (biochar as a catalyst), the key parameters to consider include surface area, porosity, texture, surface functionality (including specifically acidic-basic sites), metals nature and distribution $[10,14-17,21,23,24]$. High surface area promotes mineral distribution and favors pollutant diffusion through the porous network to the active

\footnotetext{
* Corresponding author.

E-mail addresses: sarah.berhanu@mines-paristech.fr (S. Berhanu), maxime.hervy@mines-albi.fr (M. Hervy), elsa.weiss@mines-albi.fr (E. Weiss-Hortala), henry.proudhon@mines-paristech.fr (H. Proudhon), marie-helene.berger@mines-paristech.fr (M.-H. Berger), anthony.chesnaud@mines-paristech.fr (A. Chesnaud), matthieu.faessel@mines-paristech.fr (M. Faessel), king@synchrotron-soleil.fr (A. King), doan.phamminh@mines-albi.fr (D. Pham Minh), audrey.villot@mines-nantes.fr (A. Villot), claire.gerente@mines-nantes.fr (C. Gérente), alain.thorel@mines-paristech.fr (A. Thorel), laurence.le-coq@mines-nantes.fr (L.L. Coq), ange.nzihou@mines-albi.fr (A. Nzihou).
} 
sites [25]. The organic functions promote the multi-layer adsorption of tar through hydrogen bonds or $\pi-\pi^{*}$ stacking interactions [16]. Free carbon sites or defects in the carbonaceous matrix (vacancy, insertion of $\mathrm{O}$ atoms, curved graphene fringes...) can catalyze tar cracking reactions [26]. Mineral particles initially contained in the feedstock can have a catalytic role (especially alkali and alkaline earth metal species) [27]. It has been shown that the efficiency of chars is comparable to that of metallic catalysts, although deactivation occurs more rapidly and the reaction mechanisms are not completely elucidated [13,17,28-32]. The char surface activity comes from the porosity, the mineral and metal contents, the organic function nature and amount [15-17,22,27,33-35], as well as the carbonaceous structure [16,20,23]. In the case of wood-based materials, the textural properties play a decisive role, since the fibrous structure of the original wood is usually preserved in the resulting pyrolysis chars $[17,22,36]$. The operating conditions of char production and post-treatment affect the textural properties, especially the pore size, the total pore volume, the specific surface area, the nature of the pores (opened or closed) [15-17,22,27,33-35]. The pyro-gasification conditions (temperature and atmosphere) and post-treatments (activation, oxygenation) also impact porosity development. First, temperature impacts polymer degradation, which leads to pore creation and may limit tar condensation in the porous network [17]. Second, the use of a carbon dioxide atmosphere increases pore development compared to other atmospheres [17]. Third, chars post-treated in steam or oxygen-rich atmosphere develop a high porous network and such processes commonly result in activated carbons [15,21,22,37]. However, the usual characterization techniques do not enable to show the interconnectivity and the geometry of the pores. These latter features are of great interest since the gas diffusion is pore diameter limited, and tar could be condensed in the porous network. Therefore, as shown by previous studies, a better understanding of the macrostructure involves char imaging [38-41]. Moreover, it is worth noting that the porosity development will impact the carbonaceous matrix since graphene fringes are supposed to be reorganized [23,42-44]. However, the techniques employed in most studies are mainly based on the adsorption of gases or mercury intrusion in order to investigate the porosity either at different scales. These methods do not enable to visualize the pores and their distribution within the carbonaceous matrix. Besides, they do not provide information on the chemical composition of the carbonaceous matrix and the various types of carbon structures that may be present in it and affect char reactivity. Finally, chars are also characterized by the total amount and the surface distribution of mineral and metal species [24]. It has been shown that mineral clusters could clog the pores at the surface $[17,22,27,32,33]$, which would impact the interconnected porosity in the resulting chars.

This work aims at describing in further detail the carbonaceous matrix in wood-based chars. Macro-, micro- and nanostructures were investigated using a combination of advanced characterization techniques in order to understand the structural changes occurring during char fabrication and post-treatment. The types and relative amounts of the various carbon structures were also determined. To our knowledge, it is the first time that such a method is applied to reveal the structural evolution that the char carbonaceous matrix undergoes during the fabrication process. Thanks to this approach, a precise description is obtained, enabling a full characterization of the char structural features and a discussion on its potential use as catalyst for tar cracking. This work will have direct implications for char engineering and could be also of interest for other types of applications.

Three types of wood-based chars were analyzed in this study. In order to observe the structural changes occurring over pyro-gasification, wood feedstock was used to produce chars at two pyrolysis temperatures $\left(400\right.$ and $700{ }^{\circ} \mathrm{C}$ ). In addition, to understand the modifications resulting from activation, the $700{ }^{\circ} \mathrm{C}$ char was post-treated under steam at $850^{\circ} \mathrm{C}$. Characterization at the macroscopic scale involved imaging of the sample in three dimensions by X-Ray synchrotron microtomography. The degree of ordering of the carbonaceous matrix (graphene fringe stacking, fringe orientation, aromaticity, crystallite size, etc.) was studied using transmission electron microscopy, Raman spectroscopy, and X-ray diffraction. These latter two techniques also allowed to quantify the relative amounts of the various carbon structure types composing the char. All these advanced analytical techniques were combined to provide a better understanding of the char structure and to discuss the expected reactivity.

\section{Materials and methods}

\subsection{Char preparation and basic characterization}

Three types of pyrolysis chars were produced from wood of used pallets (WUP) that were utilized on cruise ships. WUP was common softwood (from gymnosperm trees) used in the production of pallets for loading and transportation of food. The chars as well as the raw material considered in this study were all composed of small fragments such as twigs or millimetric blocks. For each type of char, characterization was carried out, except for X-Ray synchrotron microtomography, on several fragments and when applicable on different locations. This ensured that the observations were related to the fabrication process and not to possible intrinsic heterogeneities. The pyrolysis chars were produced in a semi-continuous screw reactor (internal diameter of $0.167 \mathrm{~m}$ and $2 \mathrm{~m}$ in length) by slow pyrolysis of WUP in order to maximize the char formation yield. Char c.WUP400 was obtained by pyrolysis at $400^{\circ} \mathrm{C}$ during $30 \mathrm{~min}$, with a heating rate of $10^{\circ} \mathrm{C}$.min ${ }^{-1}$. Char c.WUP700 was produced by pyrolysis at $700{ }^{\circ} \mathrm{C}$ for $30 \mathrm{~min}$, with a heating rate of $22^{\circ} \mathrm{C} . \mathrm{min}^{-1}$. These temperatures were selected as they are representative of low and high conventional pyrolysis temperature, respectively. The details of the experimental procedure were described in a previous paper [45]. The activated char a.c.WUP700 was produced by pyrolysis of char c.WUP700: a sample of $100 \mathrm{~g}$ of c.WUP700 was introduced in a semi-rotation reactor in quartz (Carbolite HTR 11/150), and heated to $850^{\circ} \mathrm{C}$ in an inert atmosphere (nitrogen flow rate $=0.5 \mathrm{~L} \mathrm{~min}^{-1}$ ) with a heating rate of $10^{\circ} \mathrm{C} \mathrm{min}{ }^{-1}$. Once this temperature was reached, steam was added in the nitrogen flow at a concentration of 15 vol.\%. This activation process was carried out under these conditions for $80 \mathrm{~min}$. The char formation yield was $22 \mathrm{wt} \%$ for c.WUP700 and $77 \mathrm{wt} \%$ for a.c.WUP700.

As a first step, the chars were characterized using common techniques such as scanning electron microscopy and mercury porosimetry (results shown in Fig. 8 and Table 5 in Supporting Information). The sample macrostructure was typical of that of wood-based materials and, as the pyrolysis temperature was raised or activation was carried out, the char surface became rougher with nanoporosities and outcropping particles. Mercury porosimetry showed that higher pyrolysis temperatures resulted in an increase of the total pore area and of the mesoporous volume. The activation step also increased the total pore area of the materials. This increase is mainly explained by the development of the microporous and macroporous volume, corresponding to the material roughness. The mesoporous volumes measured in this study are in agreement with those measured by other researchers for similar materials [46].

\subsection{Synchrotron microtomography}

The three-dimensional (3D) macrostructure of the samples was assessed by X-Ray microtomography. For each sample, a twig-shaped fragment of roughly $1 \mathrm{~mm}^{2} \times 1 \mathrm{~cm}$ was selected. X-Ray microtomography scans were acquired on the PSICHÉ beamline at the SOLEIL synchrotron. The tomographic setup used a monochromatic parallel beam at $32 \mathrm{keV}$, with a size of $1.4 \mathrm{~mm}$ in both directions, which illuminated the char sample glued vertically on the rotation table. Attenuated X-rays were collected by the Hamamatsu CMOS 2k detector via a $10 \times$ magnifying optics to form a radiograph. A tomographic scan 
corresponded to a set of 1000 radiographs, recorded over a $180^{\circ}$ rotation. One image was recorded every $3.5 \mathrm{~s}$, resulting in a scan duration of $\sim 1 \mathrm{~h}$. The distance between the specimen and the camera was set to $40 \mathrm{~mm}$ which led to a good combination of absorption and phase contrast. The size of the isotropic voxels in the reconstructed volumes was $0.65 \mu \mathrm{m}$.

After acquisition, the different sets of two-dimensional (2D) radiographs were processed by the state of the art PyHST reconstruction software [47] installed at SOLEIL. The Paganin algorithm [48], implemented in PyHST, was used to take advantage of the phase contrast between the air and the carbon matrix, since the carbon matrix had a very low absorption. Using the phase contrast with the Paganin algorithm provided a good signal to noise ratio and considerably eased the subsequent image analysis process to study the pore morphologies. The tomographic scans were processed by automated 3D image analysis to separate the wood phase from the interior cavities and the exterior. An in-house code combining state of the art Python and VTK routines was used on a subset of 500 slices corresponding to a height of $325 \mu \mathrm{m}$ in each volume. The subset was chosen to keep the computation time reasonable while containing a statistically relevant number of pores (typically several thousands). The segmentation procedure was carried out as follows: first the volumes were rotated in plane to align the pore network with the $\mathrm{X}, \mathrm{Y}$ directions. A watershed transform was then applied using markers at both ends of the histogram to obtain respectively the void and the wood phases. For this work we have used the implementation available in the Python scipy package [49]. Since most of the voids were connected to the outside air, morphological closing operations were also used to separate them from the air. Interior voids were then labeled individually based on their connectivity (using a cross-shape structuring element). This way, communicating cells were given a unique label and can be displayed with the same color. Based on this segmentation, the wood volume fraction and surface to volume ratio could be computed. The size of the individual connected cavities was measured as the Feret diameters with respect to the $\mathrm{X}, \mathrm{Y}, \mathrm{Z}$ axes. The $\mathrm{Z}$ value although computed was not studied here since the cells typically cross the whole volume (even considering the 2048 slices ie. $1.3 \mathrm{~mm}$ ). One should note that since the cavities are very elongated in the $\mathrm{Z}$ direction, the connection network for a given volume depends on the height considered. The different steps in the experimental procedure and image processing led to an error of $\sim 4 \mu \mathrm{m}$ on the in plane dimension determination.

\subsection{Transmission electron microscopy}

Transmission electron microscopy (TEM) samples were prepared by ultramicrotomy using a LEICA Ultracut R Ultramicrotome. Char fragments of approximatively $2-3 \mathrm{~mm}^{2} \times 1 \mathrm{~cm}$ were inserted into standard BEEM capsules (Agar Scientific) and embedded in an epoxy resin in order to produce blocks with a pyramidal top well-suited for cutting operation. The resin polymerization was carried out at $55^{\circ} \mathrm{C}$ for $4 \mathrm{~h}$. Such a resin is well-known to provide appropriate results in terms of cutting quality for carbon-graphite materials [50]. After being removed from the mold, the block top was perfectly flattened using a diamond trimming tool $45^{\circ}$ (DiATOME). Thin slices of $\sim 100 \mathrm{~nm}$ thickness were then cut using a $35^{\circ}$ ultra diamond knife (DiATOME) at a cutting speed of $1 \mathrm{~mm} \mathrm{~s}^{-1}$ and a clearance angle of $6^{\circ}$. The undamaged rectangular sections floating on the surface of the water bath were gently collected with a perfect loop and transferred onto 300 square mesh gold grids (Agar Scientific). TEM characterization was performed using a FEI Tecnai F20 ST TEM, operated at $200 \mathrm{kV}$ and equipped with a field emission gun (FEG) electron source. High angle annular dark field (HAADF) images were acquired in scanning TEM (STEM) mode using a Model 3000 Annular Dark Field detector (Fischione Instruments). The 002 lattice fringe mode - referred later to as high resolution (HR) - was used to image the profile of the aromatic layers (extent and shape) on the thinnest parts of the samples. The HRTEM images were acquired with drastic care at a magnification of 700000 times, and at about the Scherzer optimum underfocus $(-55.88 \mathrm{~nm})$ to obtain reliable and consistent data with a spatial resolution of $0.028 \mathrm{~nm}$.

\subsection{Mathematical morphology analysis of HRTEM images}

In order to characterize the nanostructure of samples c.WUP700 and a.c.WUP700, a method based on the mathematical morphology analysis of HRTEM images was used. This method is fully described elsewhere [51] and provides statistical information on features of the graphene sheets composing the material matrix. For each sample, a set of HRTEM images was processed using the mathematical morphology analysis software, resulting in an area of at least $1500 \mathrm{~nm}^{2}$ being analyzed per char. The fringe length, the tortuosity, the local curvature radius and the number of graphene sheets forming locally a stack of parallel fringes were then determined. The individual fringe length was simply deduced by counting the number of its constitutive pixels, whilst their tortuosity was derived from the ratio of their length to the Euclidean distance between their two ends. The local curvature radius was computed at every point of the fringe, by searching the circle radius matching the best the curvature of the fringe fragment composed of the central point and its next four pixels on each side.

\subsection{Raman spectroscopy}

Raman spectroscopy was used to analyze the different carbon structures of the carbonaceous solids. Raman spectra were acquired using a Confocal Raman - AFM WITEC Alpha 300AR microscope equipped with a CCD camera detector $\left(175-4000 \mathrm{~cm}^{-1}\right)$ at room temperature in air. Spectra were recorded using a $50 \times$ lens $(\mathrm{Na}=0.75)$ and an excitation laser at $532 \mathrm{~nm}$. Each char was analyzed on at least two zones at the surface (on a square of $5 \times 5 \mu \mathrm{m}^{2}$ ) and for a depth of $3 \mu \mathrm{m}$. Spectra were then compared in each zone and an average spectrum was used for curve-fitting. Details of the procedure used for spectrum analysis are given in Supporting Information.

\subsection{X-ray diffraction}

The carbon structures present in the chars were further assessed by $\mathrm{X}$-ray diffraction (XRD). X-ray powder diffraction (XRPD) measurements were carried out at room temperature using a Philips Panalytical X'pert Pro MPD diffractometer equipped with an X'celerator linear detector which simultaneously measures data within $\sim 2.1^{\circ}$ in $2 \theta$ (equivalent to 127 point detectors simultaneously collecting data). XRPD patterns were collected with a Cu Ka radiation source (1.541 $\AA$ ) operating at $45 \mathrm{kV}$ and $40 \mathrm{~mA}$. The whole diffraction pattern was collected between $2 \theta=9^{\circ}$ and $2 \theta=75^{\circ}$ with a step size of $0.033^{\circ}$ in $2 \theta$ and an integration time of about $30 \mathrm{~s}$ per step leading to a total collection time of $33 \mathrm{~min}$ for each sample. A silicon standard material was used to calibrate the $2 \theta$ scale of the diffractometer. The phase identification of the diffraction pattern was performed using the JCPDS database. The procedure used for data analysis and interpretation is described in Supporting Information.

\section{Results}

The structural properties of chars are routinely characterized by scanning electron microscopy. Although this technique provides valuable information, it can only give an incomplete overview of the 3D structure of the material. Particularly, in the case of wood-based samples, a 3D porous structure exists at the macroscopic scale, with several levels of organization [52]. Basically, the four materials considered in this study consisted of a regular assembly of hollow, elongated, parallel fibers referred to as tracheid cells (Fig. 8 in Supporting Information). Periodically, another set of transversally-orientated cells - the ray parenchymae - crossed the structure perpendicularly. Consequently, it 

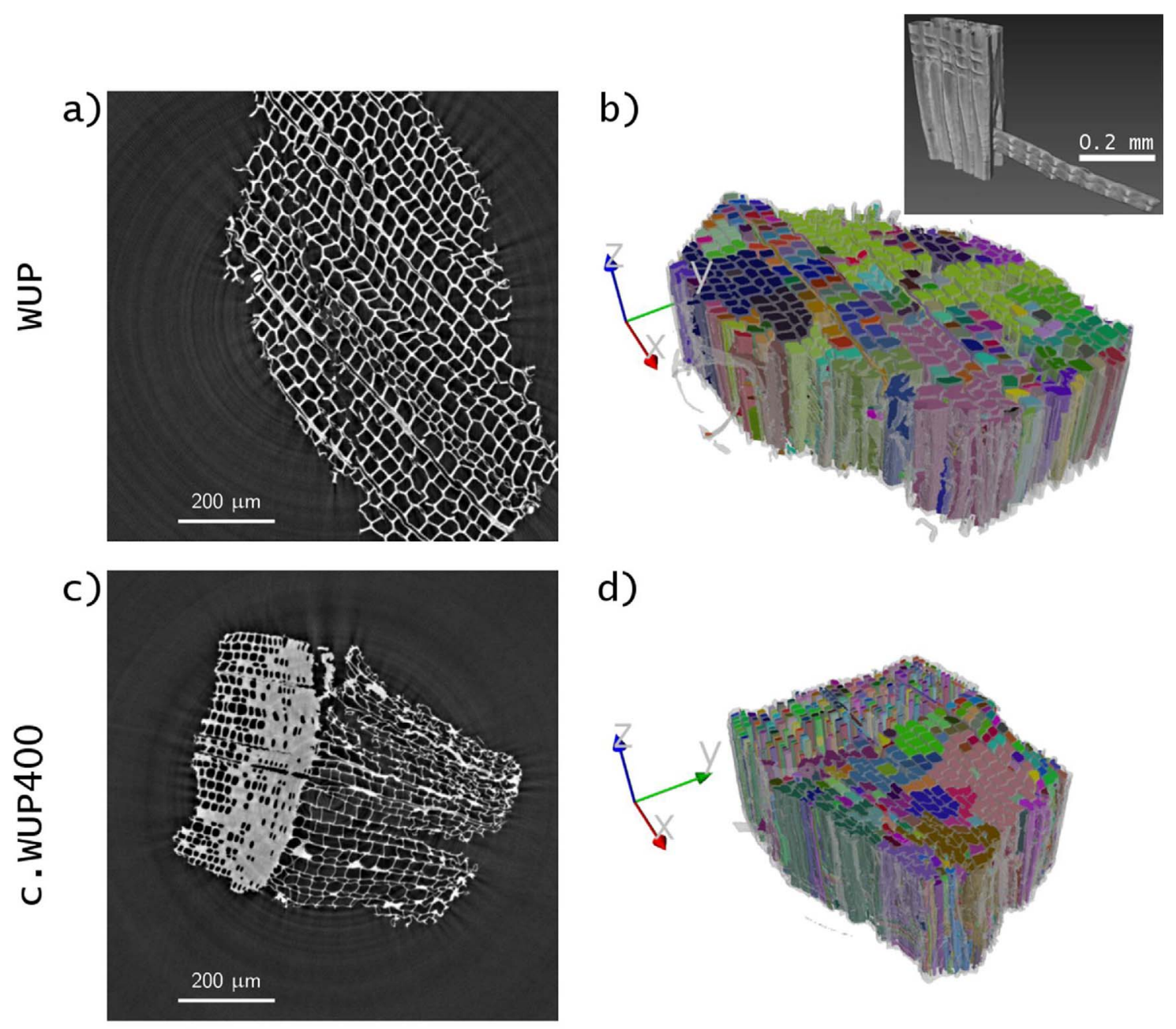

d)
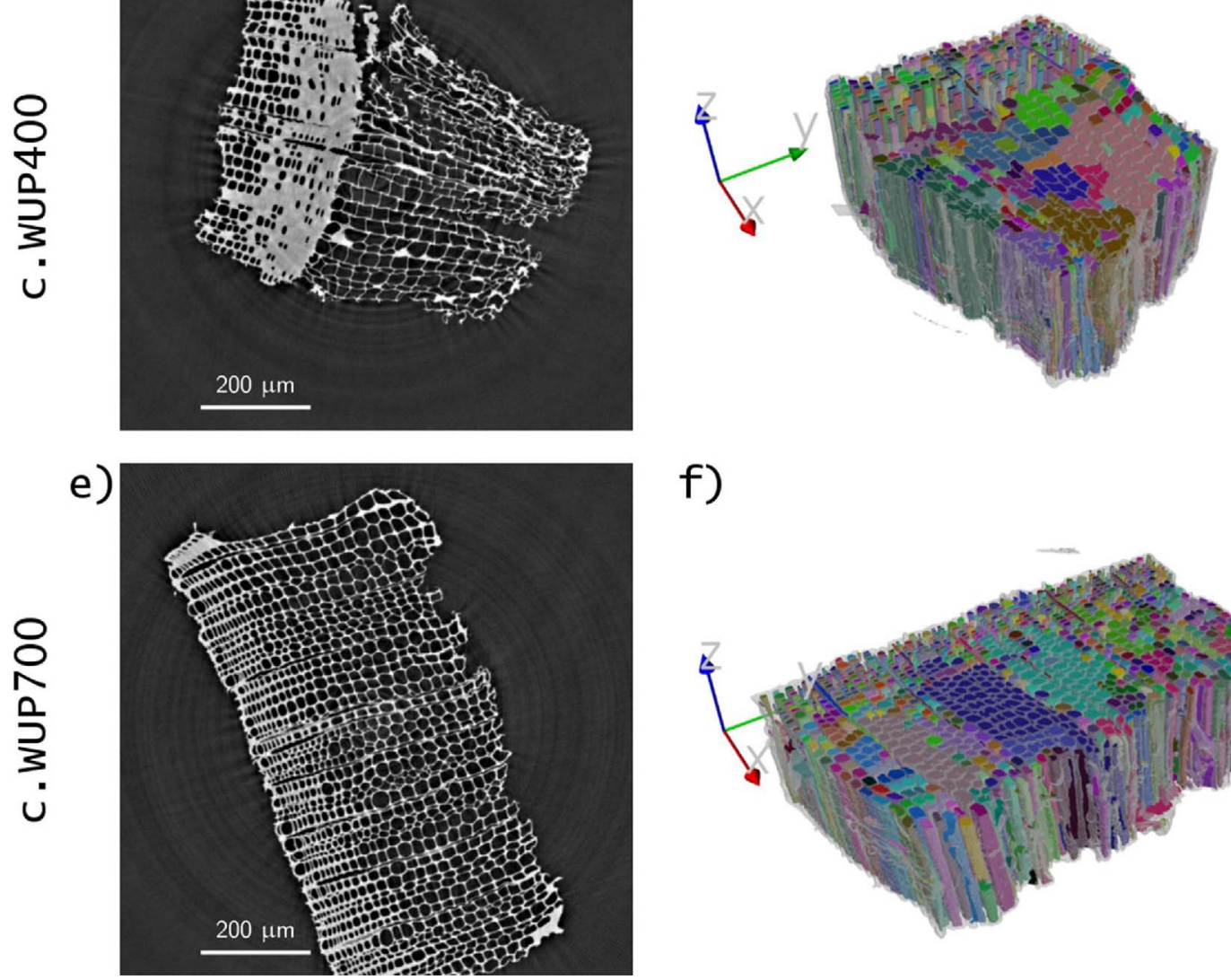

f)

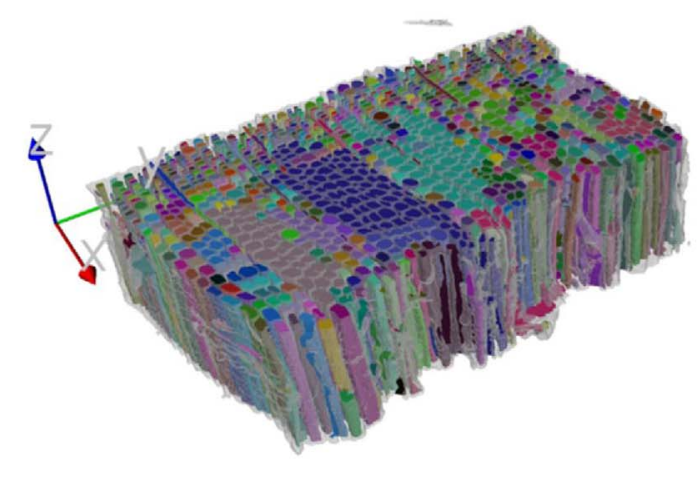

Fig. 1. 2D XY cross-sections and 3D volumes reconstructed from X-ray synchrotron microtomography scans for samples WUP (a and b), c.WUP400 (c and d), c.WUP700 (e and f). The solid phase is shown in light gray and the pores in color. The axis length in b), d) and f) is $200 \mu \mathrm{m}$. The inset in b) shows an example of connected pores. The $2 \mathrm{D}$ XY cross-sections are shown here as reconstructed and were rotated according to the pore network for further analysis.

would be interesting to describe more precisely the cell geometry, organization, and interconnection. The macroporous structure of samples WUP, c.WUP400 and c.WUP700 was thus further assessed using X-ray synchrotron microtomography. Reconstructed 2D and 3D images are shown in Fig. 1 and quantitative data were extracted (Table 1). However, as only one twig per sample could be scanned because of time constraints, one should be cautious in the interpretation of the results. For a detailed comparison of the materials, several fragments should be analyzed in order to obtain a reliable statistical dataset. Nevertheless, the samples could be here qualitatively described and trends on the pore size distribution could be seen (Fig. 2). Reconstructed 2D crosssections unveiled the internal structure and its porous, regular organization of longitudinal and transverse cells (Fig. 1a, c and e). One can notice regions of higher density due to thicker walls - as for sample c.WUP400 (Fig. 1c) - or due to smaller tracheid cell diameters - as for sample c.WUP700 (Fig. 1e). This is an indication of the variety of macrostructures that can be found in one specimen. Scans were concatenated to reconstruct 3D volumes and the solid phase was displayed 
Table 1

Data extracted from the analysis of the X-ray synchrotron microtomography scans.

\begin{tabular}{|c|c|c|c|c|}
\hline & & WUP & c.WUP400 & c.WUP700 \\
\hline \multicolumn{2}{|l|}{ Solid volume fraction } & 0.42 & 0.50 & 0.49 \\
\hline \multicolumn{2}{|c|}{ Surface to volume ratio $\left(\mu \mathrm{m}^{-1}\right)$} & 0.53 & 0.47 & 0.56 \\
\hline \multirow[t]{3}{*}{$\mathrm{X}$ Feret diameter $(\mu \mathrm{m})$} & Mean & 36 & 29 & 28 \\
\hline & Median & 25 & 19 & 21 \\
\hline & Standard deviation & 57 & 27 & 26 \\
\hline \multirow[t]{3}{*}{ Y Feret diameter $(\mu \mathrm{m})$} & Mean & 19 & 15 & 21 \\
\hline & Median & 10 & 11 & 10 \\
\hline & Standard deviation & 34 & 18 & 21 \\
\hline
\end{tabular}

in light gray whereas the pores were shown in color. To illustrate the pore interconnectivity, a color code was applied: communicating cells were displayed in the same color (Fig. 1b, d, and e). For the three samples, a vast majority of the tracheid cells were interconnected. It can be noted that the reconstruction was carried out over a Z-length of $325 \mu \mathrm{m}$, meaning that even more tracheid cells were communicating over the full twig length. One can then assume that access to a large fraction of the material volume would be easily provided for a diffusing medium, such as a gas. An example of an ensemble of connected pores is shown in inset of Fig. 1b. This ensemble is also displayed in a video available in electronic supplementary content. It can be observed that the interconnection between the tracheid cells is also ensured by transverse cells. Using these 3D reconstructed volumes, the solid volume fraction and the tracheid cell dimensions could be measured. However, only the $\mathrm{X}$ and Y Feret diameters were evaluated as most of the pores did not fit in the detector field of view in the $\mathrm{Z}$ direction. After pyrolysis, the solid volume fraction increased from 0.42 for the raw material (WUP) to 0.50 for c.WUP400 and 0.49 for c.WUP700. This may suggest a densification of the material structure during char fabrication mainly explained by the release of light organic compounds from the wood. No significant difference in terms of surface to volume ratio was found between the three specimens. The pore size distribution was widely spread for the three samples, as indicated by the results shown in Table 1 (large standard deviation values). However, the mean Feret diameters compared well to dimensions measured by SEM $(\sim 20 \mu \mathrm{m})$. This large pore size distribution is due to the presence of longitudinal and transverse pores as well as to irregularities in the tracheid cell dimensions observed in one twig. The histograms of the $\mathrm{X}$ and Y Feret diameters are given for sample c.WUP700 in Fig. 2 to illustrate this phenomenon. Feret diameters below $\sim 50 \mu \mathrm{m}$ corresponded to longitudinal pores, which formed the major fraction of the porosity. Transverse pores, on the contrary, led to larger Feret diameters and were less frequently found. The higher occurrence of longitudinal pores with respect to transverse pores is also illustrated by the fact the median $\mathrm{X}$ and $\mathrm{Y}$ Feret diameters were smaller than the mean ones.

The sample micro- and nanostructure was studied in greater detail using TEM and typical results are shown in Fig. 3. Sample WUP was very fragile under the electron beam and it was difficult to acquire images. It exhibited an amorphous isotropic structure, as confirmed by the fast Fourier transform (FFT) image obtained from the region shown in the inset (Fig. 3a). For the c.WUP400 char, a heterogeneous microstructure was observed and the selected area electron diffraction (SAED) ring pattern was typical of a nanocrystalline material (Fig. 3b). At higher magnification one could indeed distinguish many crystallites of a few nanometers in size embedded in the carbonaceous matrix. Further energy dispersive X-ray spectroscopy analysis revealed that this char contained a significant amount of elements such as $\mathrm{O}, \mathrm{Fe}, \mathrm{Si}$ or $\mathrm{P}$ (not shown here) but it was not possible to assign the rings of the SAED pattern to a definite crystalline structure with certainty. The c.WUP700 and a.c.WUP700 samples possessed a more homogeneous microstructure in terms of density (Fig. $3 \mathrm{c}$ and d). Moreover, the SAED diffuse ring patterns were indicative of an isotropic vitreous structure at the nanoscale. The SAED ring diameters matched inter-reticular distances of $0.35-0.40 \mathrm{~nm}, 0.21 \mathrm{~nm}$ and $0.12 \mathrm{~nm}$. Such reflections may be assigned to the (002), (100) + (101), and (110) + (112) atomic planes of a graphitic structure. A lamellar organization could be seen at the edges of these two samples. The graphene sheets could also be just distinguished at higher magnification (insets of Fig. $3 \mathrm{c}$ and d). Besides, the presence of nanoporosities measuring $\sim 20-50 \mathrm{~nm}$ was confirmed for the activated char (a.c.WUP700) using the high angle annular dark field (HAADF) mode. These nanoporosities can be seen in dark gray in the bottom left inset of Fig. 3d. They corresponded to regions where fewer counts were detected by the HAADF detector, confirming the lesser amount of matter and thus the presence of pores.

The nanoscale structure was further assessed by acquiring HRTEM images on the thinnest parts of samples c.WUP400, c.WUP700 and a.c.WUP700 (Fig. 4). For the char prepared at $400{ }^{\circ} \mathrm{C}$ (Fig. $4 \mathrm{a}$ and b), crystallized nanoparticles were embedded in the carbonaceous matrix, which was in agreement with the TEM results discussed previously. No graphene fringes were visible, suggesting that the pyrolysis temperature
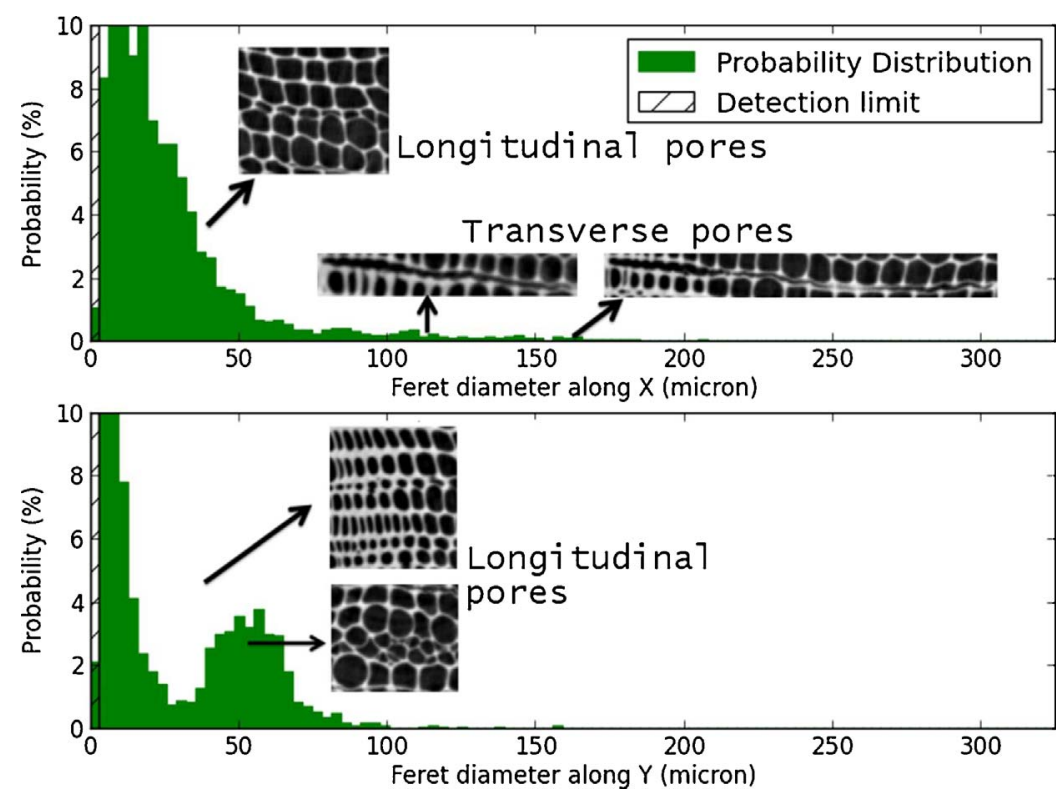

Fig. 2. Histograms of the Feret diameters along the $\mathrm{X}$ and $\mathrm{Y}$ directions illustrating the pore size distribution for sample c.WUP700. 

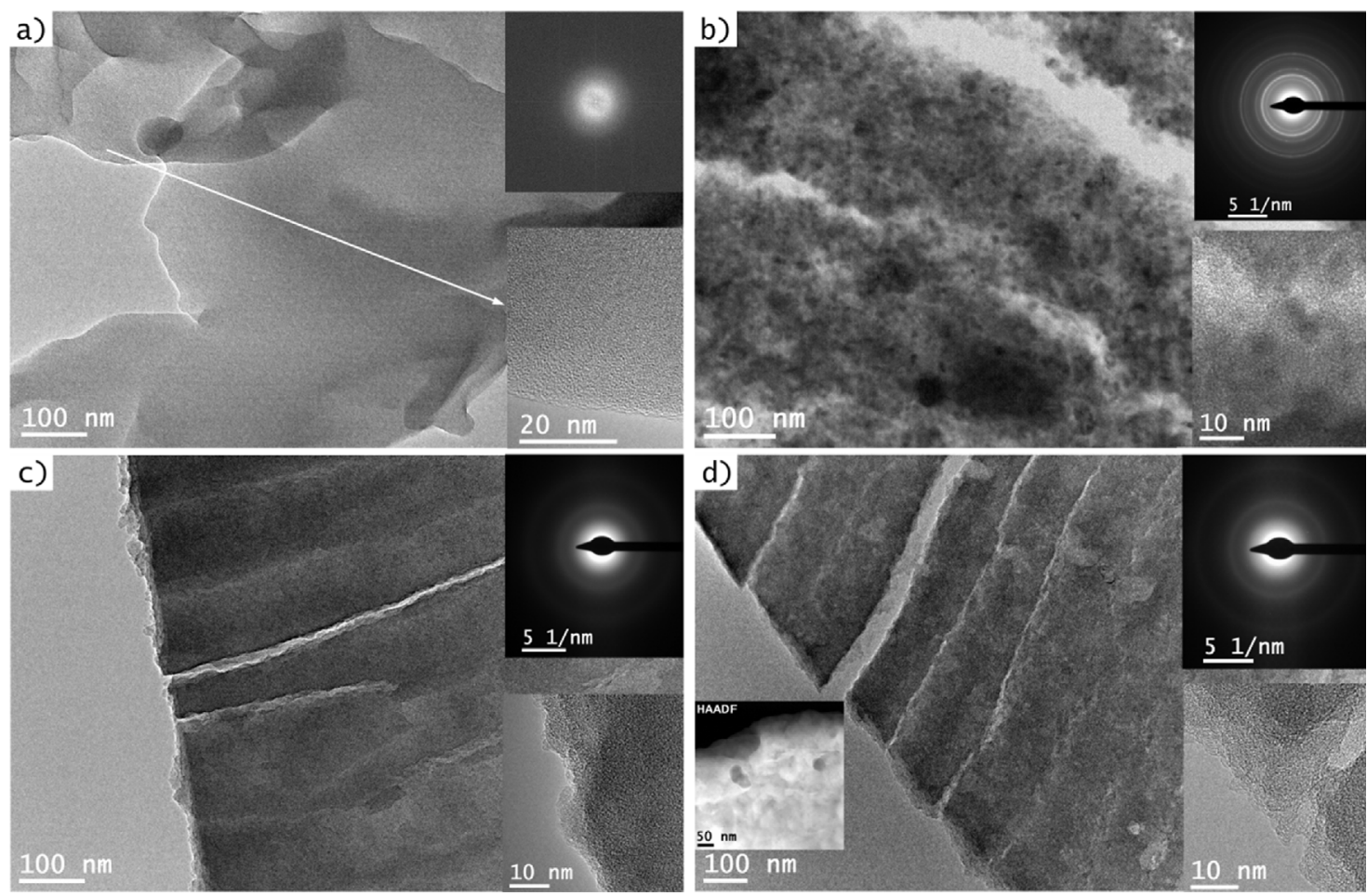

Fig. 3. Transmission electron micrographs of samples WUP (a), c.WUP400 (b), c.WUP700 (c), and a.c.WUP700 (d). Insets show on the top right corner the corresponding FFT or SAED pattern and on the bottom right corner details of the nanostructure. Inset on the bottom right corner of picture d: imaging in HAADF mode reveals the presence of nanoporosities.

was not high enough to lead to the formation of graphene sheets. On the contrary, for samples c.WUP700 and a.c.WUP700, only graphene fringes were seen (Fig. $4 \mathrm{c}-\mathrm{f}$ ). The pyrolysis temperature rise seemed thus to result in the disappearance of the crystallized nanoparticles in the bulk of the material and in the partial graphitization of the carbonaceous matrix. The graphene sheets arranged themselves in a turbostratic structure with an isotropic short-range ordering. The activated char seemed to possess a slightly more ordered structure, with the graphene fringes forming locally onion-like layers.

In order to characterize in more detail the graphene sheet arrangement, an approach based on mathematical morphology was used. The fringe length, tortuosity, local curvature radius were estimated for c.WUP700 and a.c.WUP700 and results are summarized in Table 2. The fringe length and the local curvature radius did not vary significantly between the two samples. However, the mean tortuosity increased by almost 7\% after the activation step while its standard deviation was reduced by almost $60 \%$. This suggests that a more regular turbostratic structure is obtained for sample a.c.WUP700 and confirms the HRTEM image observation.

The graphene fringes also arranged themselves locally in small stacks of parallel layers. These domains could be identified using the mathematical morphology software and the number of parallel layers for each stack could be determined. As can be seen in Fig. 5, for both materials, most of these stacks are composed of 2-4 layers. The activated char exhibited a slightly higher fraction of 3-4 layer stacks, suggesting a more ordered structure induced by the activation step.

Another way to characterize the char structure relies on Raman spectroscopy and therefore samples c.WUP400, c.WUP700 and a.c.WUP700 were studied using this technique. The normalized Raman spectra at the first order of the three chars are shown in Fig. 6. The three spectra were typical of short-range ordered and disordered materials since the two main broad bands ( $G$ and $D$ ) were observed. However, differences could be noted between the three spectra. First, the spectrum from c.WUP400 was characterized by shoulders below $1100 \mathrm{~cm}^{-1}$ of Raman shift as well as above $1700 \mathrm{~cm}^{-1}$. Second, for samples c.WUP400 and c.WUP700 a higher intensity was recorded for the G band compared to the D band, whereas the activated char showed a reverse trend. Third, the D band was shifted to lower values of Raman shift as the pyrolysis temperature was increased and also as activation was carried out. In addition, the height of the valley between the D and $\mathrm{G}$ bands also decreased with the severity of the treatment. These features can be considered to discuss the distribution of the different carbon structures in the three chars.

The shoulder observed between 800 and $1100 \mathrm{~cm}^{-1}$ in c.WUP400 spectrum could be due to volatile compounds which were condensed on the surface of the char at this temperature and were not already polymerized [53]. The second shoulder above $1700 \mathrm{~cm}^{-1}$ is likely to be due to carbonyl structures which are stable until $800^{\circ} \mathrm{C}$ [54-56].

The increase in pyrolysis temperature decreased the amount of aliphatic structures $\left(\mathrm{I}_{\mathrm{I}} / \mathrm{I}_{\text {tot }}\right)$ as seen in Table 3 by comparing data for c.WUP400 and c.WUP700. One can also observe that the temperature rise led to a greater amount of the graphene and graphene-like sheets $\left(\mathrm{I}_{\mathrm{G}} / \mathrm{I}_{\text {tot }}\right)$ and disordered graphitic structures $\left(\mathrm{I}_{\mathrm{D}} / \mathrm{I}_{\text {tot }}\right)$, while the amorphous content decreases (see $\mathrm{I}_{\mathrm{D}}$ "/ $\mathrm{I}_{\text {tot }}$ ratio in Table 3 and height of the valley in Fig. 6). In addition, the $\mathrm{G}$ band maximum was shifted from $1587 \mathrm{~cm}^{-1}$ (c.WUP400) to $1599 \mathrm{~cm}^{-1}$ (c.WUP700) of Raman shift (Fig. 6). This trend is in agreement with the literature and means that graphitic nanocrystallites (very short order) and curved graphene-like fringes were developed in the structure [57]. Although the main part of the "graphitic structure" is disordered, the peak ratio describing the total amount of "graphitic structure" increased with the temperature from 58.2 to $82.6 \%$.

The Raman spectrum of the activated char (a.c.WUP700) showed a higher intensity for the D band than for the G band. Simultaneously, the fraction of amorphous structure $\left(\mathrm{I}_{\mathrm{D}} " / \mathrm{I}_{\text {tot }}\right.$ ratio in Table 3 and the height of the valley in Fig. 6) was significantly reduced. Data in Table 3 shows that graphene and graphene-like sheets (G band) and disordered graphitic structures (D, D' and I bands) increased with the activation treatment and were the main carbon structures of the activated char (84.2\%)

In conclusion, Raman spectroscopy showed that the fractions of disordered graphitic structures with a very short order (D band, 

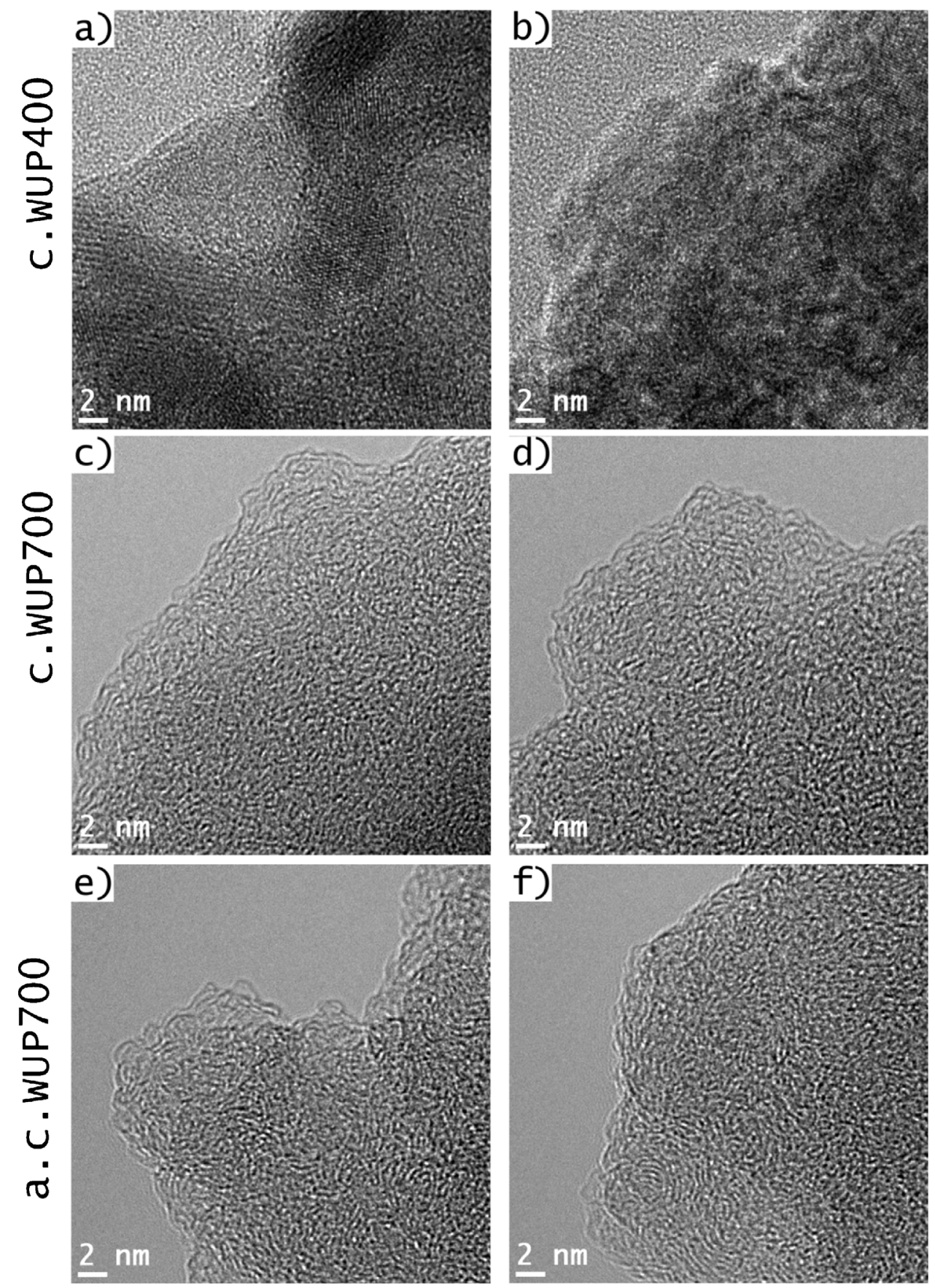

Fig. 4. HRTEM micrographs of samples c.WUP400 (a and b), c.WUP700 (c and d), and a.c.WUP700 (e and f).

Table 2

Graphene fringe features calculated by mathematical morphology analysis for samples c.WUP700 and a.c.WUP700.

\begin{tabular}{|c|c|c|c|c|c|c|}
\hline \multirow[t]{2}{*}{ Sample } & \multicolumn{2}{|l|}{ Fringe length } & \multicolumn{2}{|l|}{ Tortuosity } & \multicolumn{2}{|c|}{ Local curvature radius } \\
\hline & Mean (nm) & Standard deviation (nm) & Mean & Standard deviation & Mean (nm) & Standard deviation (nm) \\
\hline c.WUP700 & $1.82 \pm 0.03$ & 2.15 & $2.65 \pm 0.03$ & 2.88 & 0.76 & 0.88 \\
\hline a.c.WUP700 & $1.87 \pm 0.04$ & 2.42 & $2.83 \pm 0.01$ & 1.16 & 0.78 & 0.90 \\
\hline
\end{tabular}

turbostratic carbon) were increased with the severity of the treatment (pyrolysis and activation). The total amount of graphite and graphitelike structures rose from $58.2 \%$ to $82.6 \%$ by changing the pyrolysis temperature from $400{ }^{\circ} \mathrm{C}$ to $700{ }^{\circ} \mathrm{C}$, and reached $84.2 \%$ after activation. At the same time, the amount of amorphous structures was lowered.
XRD patterns recorded on c.WUP400, c.WUP700 and a.c.WUP700 are shown in Fig. 7. Two peaks were observed at $d \approx 2.08$ and $3.80 \AA$, which correspond to the (100) and (002) graphite planes respectively.

The parameters calculated from the XRD patterns are shown in Table 4. Deconvolution of the (002) peak and the $\gamma$-band was carried 


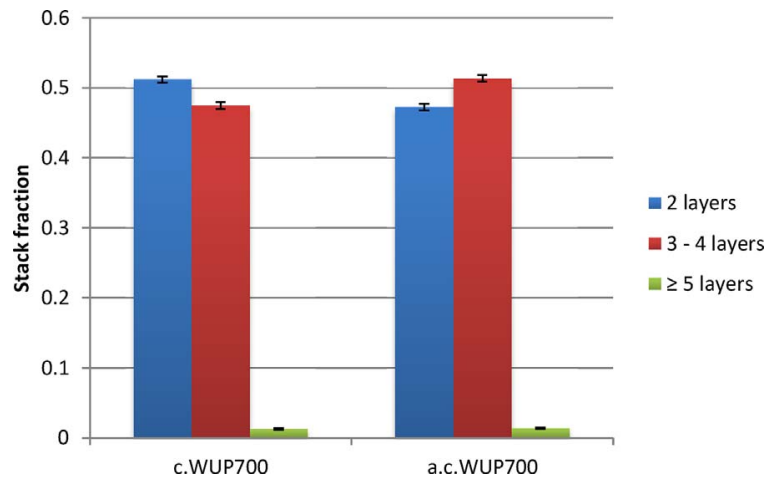

Fig. 5. Distributions of the number of layers composing stacks of parallel graphene fringes for samples c.WUP700 and a.c.WUP700. The error margins with a confidence interval of $95 \%$ were below 0.01 .

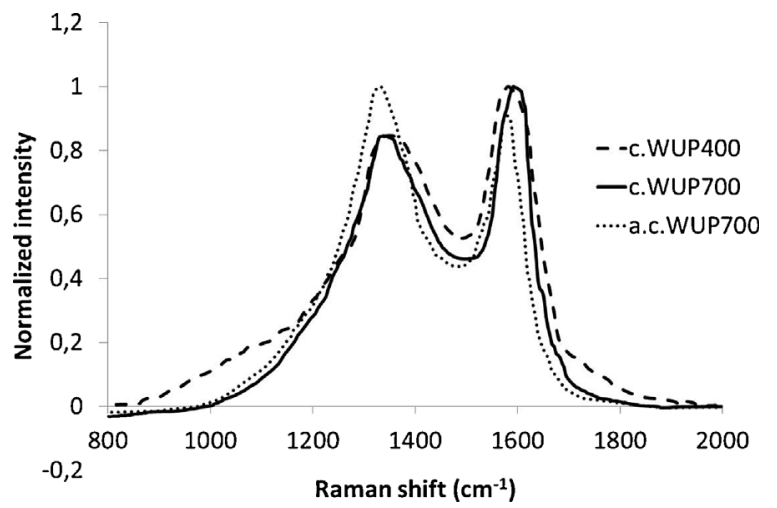

Fig. 6. Normalized Raman spectra of samples c.WUP400, c.WUP700 and a.c.WUP700.

Table 3

Values of various peak ratios obtained from the deconvolution of the Raman spectra.

\begin{tabular}{|c|c|c|c|}
\hline & c.WUP400 & c.WUP700 & a.c.WUP700 \\
\hline $\begin{array}{l}\text { Graphene sheets and graphene-like } \\
\text { sheets }\left(\mathrm{I}_{\mathrm{G}} / \mathrm{I}_{\text {tot }}\right)\end{array}$ & 0.168 & 0.174 & 0.179 \\
\hline Disordered graphitic lattice $\left(\mathrm{I}_{\mathrm{D}} / \mathrm{I}_{\text {tot }}\right)$ & 0.184 & 0.408 & 0.427 \\
\hline $\begin{array}{l}\text { Disordered graphitic lattice }\left(\mathrm{A}_{1 g}\right. \\
\text { symmetry })\left(\mathrm{I}_{\mathrm{I}} / \mathrm{I}_{\mathrm{tot}}\right)\end{array}$ & 0.226 & 0.140 & 0.183 \\
\hline $\begin{array}{l}\text { Total graphitic and disordered graphitic } \\
\text { structures }\left(\left(\mathrm{I}_{\mathrm{G}}+\mathrm{I}_{\mathrm{D}}+\mathrm{I}_{\mathrm{D}},+\mathrm{I}_{\mathrm{I}}\right) / \mathrm{I}_{\text {tot }}\right)\end{array}$ & 0.582 & 0.826 & 0.842 \\
\hline Amorphous carbon $\mathrm{I}_{\mathrm{D}^{\prime \prime}} / \mathrm{I}_{\text {tot }}$ & 0.418 & 0.173 & 0.158 \\
\hline $\begin{array}{l}\text { Disordered graphitic lattice over } \\
\text { graphene sheets and graphene-like } \\
\text { sheets } \mathrm{I}_{\mathrm{D}} / \mathrm{I}_{\mathrm{G}}\end{array}$ & 1.09 & 2.35 & 2.40 \\
\hline
\end{tabular}

out (Fig. 13 in Supporting Information). When the pyrolysis temperature was increased, the (002) peak became sharper (Fig. 7) indicating an increase of the carbon crystallite size. In the same time, the interreticular distance $\mathrm{d}_{002}$ decreased when the temperature was raised (Table 4). After activation, the (002) peak became slightly sharper while its intensity decreased.

When the pyrolysis temperature was raised and also when activation was performed, the background intensity $\mathrm{I}_{\mathrm{am}}$ measured on the XRD pattern decreased, the (100) peak became sharper, and the relative area of the $\gamma$-band decreased.

\section{Discussion} 4.1. Effects of the fabrication process on the char structure-
characterization technique coupling

Advanced characterization techniques were used in this study and

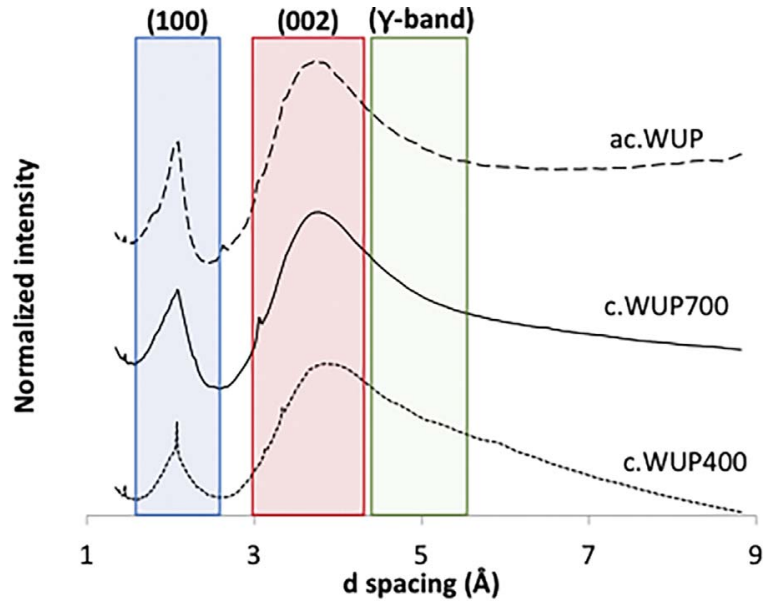

Fig. 7. XRD patterns of c.WUP400, c.WUP700 and a.c.WUP700.

Table 4

Specific parameters of chars determined from XRD pattern.

\begin{tabular}{llll}
\hline Parameter & c.WUP400 & c.WUP700 & a.c.WUP700 \\
\hline $\mathrm{d}_{002}(\mathrm{~nm})$ & 0.3849 & 0.3785 & 0.3748 \\
$\mathrm{I}_{\mathrm{am}}$ (counts) & 28,554 & 22,750 & 17,106 \\
$\mathrm{f}_{\mathrm{a}}$ & 78.7 & 87.7 & 88.2 \\
$\mathrm{~A}_{\gamma} /\left(\mathrm{A}_{002}+\mathrm{A}_{\gamma}\right)$ & 0.213 & 0.123 & 0.057 \\
\hline
\end{tabular}

provided complementary information at different scales on the structural properties of wood-based chars. The data thus gathered allowed for a better insight into our samples: the composition and organization of the carbonaceous matrix composing the chars were described qualitatively and quantitatively in detail. To our knowledge, this is the first time that such an approach, combining various tools, is applied for the study of pyrolysis chars.

The char porosity was characterized by routine techniques such as SEM and $\mathrm{Hg}$ porosimetry (results shown in Supporting Information). However, these latter techniques provide poor information on the pore geometry and interconnectivity. Here, we showed thanks to synchrotron microtomography that a vast majority of the pores were connected. At the macroscopic scale, the longitudinal and transverse cells formed an interconnected network of pores. As most of the pores were interconnected, a diffusing medium would be able to reach a large fraction of the char volume, which is promising for syngas purification. Although a greater number of samples should be probed by synchrotron microtomography for a reliable statistical analysis of the pore size distribution, the results were consistent and a trend could be seen. Bird et al. studied charcoals by X-ray microtomography for archeological purposes [58]. They observed as we did that the pyrolyzed materials retained much of the macrostructure of the parent material. However, they reported a dramatic increase in porosity after pyrolysis, which was not our case. This difference may be due to their use of slightly oxidizing conditions during pyrolysis whereas our chars were produced in an inert atmosphere.

Information on the microstructure was gathered. SEM characterization showed that a higher process temperature $\left(700^{\circ} \mathrm{C}\right.$ instead of $400^{\circ} \mathrm{C}$ ) led to a rougher surface, with particles clearly outcropping at the char surface after activation. Fig. 81 and p (in Supporting Information) images show small and well-dispersed mineral species on the char surface which provide many active sites that promote the char catalytic activity [24]. Mineral species like calcium and potassium are known to have significant catalytic activities in tar cracking reactions $[32,59,60]$, as well as iron, manganese, copper and zinc [61]. Moreover, for the chars prepared at $700{ }^{\circ} \mathrm{C}$, no more nanocrystallites were observed using TEM. Because of the sample preparation method TEM 
probed the bulk of the materials. Hence these results suggest that the increase in pyrolysis temperature favors the diffusion and reorganization of mineral and/or metal particles at the char surface.

The degree of ordering of the carbon matrix was assessed. The evolution toward a sharper (002) XRD peak when increasing the pyrolysis temperature indicated that the degree of orientation of the aromatic lamellae increased with the pyrolysis temperature, and that the char structure became more and more ordered (Fig. 8 in Supporting Information). The $\mathrm{d}_{002}$ value of the a.c.WUP700 char was lower than that of c.WUP700, indicating that despite the development of porosity the activation led to a more ordered material. This result is in agreement with literature data. Indeed, the $\mathrm{d}_{002}$ interlayer spacing is known to decrease with increase in carbon content and aromaticity [62]. The background intensity $\mathrm{I}_{\mathrm{am}}$ measured on the XRD pattern decreased when the pyrolysis temperature increased and after steam activation. This suggests that the bonds between macromolecules and the amorphous carbon were broken during the wood heating treatment, leading to the release of carbon species as volatiles. The relative area of the $\gamma$-band, which represents the aliphatic side chains grafted on the char, decreased when the pyrolysis temperature was raised and also when activation was performed. Besides, the char aromaticity (reflected by the $f_{a}$ values) increased with increasing temperatures which suggests that aliphatic side chains were not strongly bonded to char crystallites and tended to be released as volatiles during the heating. On the contrary, the aromatic rings seemed to be stable with temperature. An increase of the carbon crystallite size with increasing temperature is also reflected by the (100) peak that became sharper.

According to XRD, TEM/HRTEM and mathematical morphology results, the increase in the pyrolysis temperature resulted in a more ordered carbonaceous structure (shorter $\mathrm{d}_{002}$ interlayer spacing, increase in the crystallite size, formation of graphene sheets). Besides, these techniques showed that the activation step resulted in a rearrangement of the carbonaceous matrix with the appearance of onionlike graphene structures, higher tortuosity of the graphene fringes, higher fraction of 3-4-layer graphene stacks and larger crystallite sizes. Raman spectroscopy characterization led to similar conclusions. An increase of the amount of total "graphitic" structures and a decrease of the amorphous content were observed as for the high temperature pyrolysis char and the activated char. The abrupt change in amorphous content is in agreement with the HRTEM images shown in Fig. 4. Overall, this would mean that the amorphous content is consumed in favor to short-ordered graphitic structures.

HRTEM characterization also showed an increased in short-ordered graphitic structures such as onion-like structures after activation. Mathematical morphology analysis indicated that the stacking of graphene sheets was mainly reaching 2-4 layers for a.c.WUP700. These results mean that, although the carbonaceous matrix is more ordered at higher pyrolysis temperature and after activation, the graphitic structures formed possess a short order. This is in agreement with Raman spectroscopy data, which showed that disordered structures are in higher amount (D band and total graphitic structures ratios in Table 3) after pyrolysis at $700{ }^{\circ} \mathrm{C}$ and activation treatment. These imperfections include graphitic nanocrystallites, large aromatic rings, insertion of $\mathrm{O}$ atoms, curved graphene fringes, point defects in pure graphitic structures.

It can also be seen in Fig. 6 that the $\mathrm{G}$ band maximum was shifted from $1587 \mathrm{~cm}^{-1}$ (c.WUP400) to $1599 \mathrm{~cm}^{-1}$ (c.WUP700) of Raman shift. This trend is in agreement with the literature and means that graphitic nanocrystallites (very short order) and curved graphene-like fringes were developed in the structure [63]. After activation, a slight red-shift of both bands is observed. A red-shift in the G band position may be due to curvature induced tensile strain in fullerene-like structures as well as a partial relaxation of the compressive strain in graphitic-like network. A red-shift of the D band could originate from the nature of graphene defects (armchair or zig-zag edges) as well as "fullerene-like" defects which are involved in the curvature of the graphene sheets [57]. Regarding the activated char (a.c.WUP700), the higher D band intensity could be correlated to the presence of O-atoms between graphene layers and the increase in the number of graphite edges [64]. The $\mathrm{G}$ band is also greatly influenced by the presence of $\mathrm{O}-$ containing functional groups [57]. Therefore, the steam activation process would increase the defect density due to oxygenated groups and would favor the formation of turbostratic and short-order graphitic structures in the carbonaceous matrix.

The combination of XRD and Raman spectroscopy gave also information on the aliphatic chains. The activation treatment seemed to not impact the amount of aliphatic structures (similar $\mathrm{I}_{\mathrm{S}} / \mathrm{I}_{\text {tot }}$ ratio) but this could be due to a balance between combustion and decomposition of some aromatic rings $[65,66]$ since the activation was carried out at high temperature. On the other hand, XRD characterization suggested that aliphatic chains grafted to graphitic nanocrystallites were less numerous in the bulk after activation.

\subsection{Implications of the char structural properties on the expected catalytic activity}

Based on the results obtained in this study, the efficiency of the materials for syngas cleaning application could be discussed. Although the role of inorganics is well established in the literature [32], the focus was put here on a better understanding of the carbonaceous matrix organization, structure and composition. The carbonaceous structure of the materials has been found to be of prime importance for char gasification reactivity as well as for tar cracking. Tar is one of the most problematic pollutants of the syngas. Indeed, tar can condense at relatively high temperature, fouling and blocking the downstream applications. For this reason, it must be eliminated from the syngas before utilization.

Defects present in graphene layers were found to be active sites for methane cracking reaction [16]. Their activity results from the fact that they decrease the electronic stability of the graphene structure, leading to higher carbon reactivity. A similar activity of graphene defects can be expected for the cracking reactions of heavier hydrocarbons, such as poly-aromatic hydrocarbons. Thus, chars c.WUP700 and a.c.WUP700 may be promising candidates for the catalysis of tar cracking reactions.

Amorphous carbon, small polyaromatic rings and aliphatic structures are highly reactive with some compounds found in syngas, such as carbon dioxide and water [53,67]. Therefore, the presence of the abovementioned structures appears as an important drawback for syngas cleaning applications. Char a.c.WUP700 is the material presenting the highest ratio of graphene-like structures (very short ordered structures and graphitic-like structures) over small aromatic rings. Thus, it should not be subject to competitive gasification reaction during the tar cracking process.

Based on the literature and on the properties determined in this study, the material with the highest potential for tar cracking reactions is a.c.WUP700.

\section{Conclusions}

In this study the structural changes in the carbonaceous matrix of wood-based chars induced by the process conditions (pyrolysis temperature of 400 and $700{ }^{\circ} \mathrm{C}$ ) and post-treatment (activation) were investigated. As the role of the mineral species present on the char surface is already well established in the literature, the focus was put here on the carbonaceous matrix even though some mineral particles were observed on the samples. Advanced characterization was carried out using a combination of imaging and analytical techniques, providing a unique insight into the material properties. This approach allowed for a detailed description of the char macro-, micro-, and nanostructure. Thanks to this work the potential of each of the three chars as a catalyst for tar cracking could be discussed by taking into account previous findings from the literature. Although no significant difference was 
observed at the macroscopic scale between the samples, the fabrication process caused important structural changes at the micro- and nanometric scales. The three chars exhibited the typical macrostructural features of the parent material - wood - characterized by a network of interconnected pores. This macrostructure would greatly favor gas diffusion inside the whole char volume, which would lead to better efficiencies for syngas cleaning applications. The increase in the pyrolysis temperature resulted in the appearance of short-range ordered graphene fringes. More short-range ordered structures were formed in the carbonaceous matrix at the nanometric scale after activation. Thanks to defects contained in these graphene-like structures, more carbonaceous active sites would be formed. Therefore, based on these results and on previous reports in the literature, the activated char is expected to be a promising low-cost catalyst hydrocarbon cracking thanks to its high porosity and carbonaceous active sites. Future work will focus on testing the catalytic efficiency of the different chars discussed in this study for tar cracking reactions.

\section{Funding}

This work was supported by the "Institut CARNOT Mines" (CHARPURGAS grant, number 30530).

\section{Acknowledgement}

EWH thanks Laurène Haurie for assistance with Raman spectroscopy experiments.

\section{Appendix A. Supplementary data}

Supplementary data associated with this article can be found, in the online version, at https://doi.org/10.1016/j.jaap.2018.01.024.

\section{References}

[1] J. Lehmann, S. Joseph, Biochar for Environmental Management, Science, Technology and Implementation, 2nd edition, Routlegde, New York, 2015.

[2] J.S. Cha, S.H. Park, S.-C. Jung, C. Ryu, J.-K. Jeon, M.-C. Shin, Y.-K. Park, Production and utilization of biochar: a review, J. Ind. Eng. Chem. 40 (2016) 1-15.

[3] S. You, Y. Sik Ok, S.S. Chen, D.C.W. Tsang, E.E. Kwon, J. Lee, C.-H. Wang, A critical review on sustainable biochar system through gasification: energy and environmental applications, Bioresour. Technol. 246 (2017) 242-253.

[4] R. Zhao, N. Coles, Z. Kong, J. Wu, Effects of aged and fresh biochars on soil acidity under different incubation conditions, Soil Tillage Res. 146 (Part B) (2015) 133-138.

[5] M.M. Diémé, M. Hervy, S.N. Diop, C. Gérente, A. Villot, Y. Andres, et al., Sustainable conversion of agriculture and food waste into activated carbons devoted to fluoride removal from drinking water in Senegal, Int. J. Chem. 8 (2015) 8.

[6] M. Hervy, D.P. Minh, C. Gérente, E. Weiss-Hortala, A. Nzihou, A. Villot, et al., $\mathrm{H}_{2} \mathrm{~S}$ removal from syngas using wastes pyrolysis chars, Chem. Eng. J. (2017), http://dx. doi.org/10.1016/j.cej.2017.11.162.

[7] M. Hervy, C. Gérente, A., Villot, L. Le Coq, E. Weiss-Hortala, D. Pham Minh, et al., Recycling of pyrolysis chars from food waste, wastewater treatment sludge and wood in the syngas purification, in: Proc. Int. Conf. Solid Waste - Knowl. Transf. Sustain. Resour. Manag., J.W.C. Wong, M., Nelles, R. D. Tyagi and A. Selvam, (2015).

[8] F. Nestler, L. Burhenne, M.J. Amtenbrink, T. Aicher, Catalytic decomposition of biomass tars: the impact of wood char surface characteristics on the catalytic performance for naphthalene removal, Fuel Process. Technol. 145 (2016) 31-41.

[9] Y. Shen, M. Chen, T. Sun, J. Jia, Catalytic reforming of pyrolysis tar over metallic nickel nanoparticles embedded in pyrochar, Fuel 159 (2015) 570-579.

[10] J. Lee, K.-H. Kim, E.E. Kwon, Biochar as a catalyst, Renew. Sustain. Energy Rev. 77 (2017) 70-79.

[11] P.J. de Wild, H. den Uil, J.H. Reith, J.H.A. Kiel, H.J. Heeres, Biomass valorization by staged degasification. A new pyrolysis-based thermochemical conversion option to produce value-added chemicals from lignocellulosic biomass, J. Anal. Appl. Pyrolysis 85 (2009) 124-133.

[12] A. Demirbas, Gaseous products from biomass by pyrolysis and gasification: effect of catalyst on hydrogen yield, Energy Convers. Manage. 43 (2002) 897-909.

[13] Z. Abu El-Rub, E.A. Bramer, G. Brem, Experimental comparison of biomass chars with other catalysts for tar reduction, Fuel 87 (2008) 2243-2252.

[14] P. Serp, J.L. Figueiredo, Carbon Materials for Catalysis, Wiley, Hoboken, 2009.

[15] N. Muradov, F. Smith, A. T-Raissi, Catalytic activity of carbons for methane decomposition reaction, Catal. Today 102 (2005) 225-233.

[16] D.P. Serrano, J.A. Botas, J.L. Fierro, R. Guil-Lopez, P. Pizzaro, G. Gomez, Hydrogen production by methane decomposition: origin of the catalytic activity of carbon materials, Fuel 89 (2010) 1241-1248.

[17] N.B. Klinghoffer, M.J. Castaldi, A. Nzihou, Catalyst properties and catalytic performance of char from biomass gasification, Ind. Eng. Chem. Res. 51 (2012) $13113-13122$

[18] D. Fuentes-Cano, A. Gómez-Barea, S. Nilsson, P. Ollero, Decomposition kinetics of model tar compounds over chars with different internal structure to model hot tar removal in biomass gasification, Chem. Eng. J. 228 (2013) 1223-1233.

[19] S. Zhang, M. Asadullah, L. Dong, H.L. Tay, C.Z. Li, An advanced biomass gasification technology with integrated catalytic hot gas cleaning. Part II: Tar reforming using char as a catalyst or as a catalyst support, Fuel 112 (2013) 646-653.

[20] F.J. Wang, S. Zhang, Z.D. Chen, C. Liu, Y.G. Wang, Tar reforming using char as catalyst during pyrolysis and gasification of Shengli brown coal, J. Anal. Appl. Pyrolysis 105 (2014) 269-275.

[21] M. Ducousso, E. Weiss-Hortala, A. Nzihou, M.J. Castaldi, Reactivity enhancement of gasification biochars for catalytic applications, Fuel 159 (2015) 491-499.

[22] Y. Shen, Chars as carbonaceous adsorbents/catalysts for tar elimination during biomass pyrolysis or gasification, Renew. Sustain. Energy Rev. 43 (2015) 281-295.

[23] N. Muradov, Catalysis of methane decomposition over elemental carbon, Catal. Commun. 2 (2001) 89-94.

[24] M. Hervy, S. Berhanu, E. Weiss-Hortala, A. Chesnaud, C. Gérente, A. Villot, et al., Multi-scale characterisation of chars mineral species for tar cracking, Fuel 189 (2017) 88-97.

[25] S. Liu, Y. Wang, R. Wu, X. Zeng, S. Gao, G. Xu, Fundamentals of catalytic tar removal over in situ and ex situ chars in two-stage gasification of coal, Energy Fuels 1 (2014) 58-66.

[26] X. Li, C. Li, Volatilisation and catalytic effects of alkali and alkaline earth metallic species during the pyrolysis and gasification of Victorian brown coal Part VIII. Catalysis and changes in char structure during gasification in steam, Fuel 85 (2006) $1518-1525$.

[27] N.B. Klinghoffer, M.J. Castaldi, A. Nzihou, Influence of char composition and inorganics on catalytic activity of char from biomass gasification, Fuel 157 (2015) $37-47$.

[28] B. Fidalgo, J.Á. Menéndez, Carbon materials as catalysts for decomposition and $\mathrm{CO}_{2}$ reforming of methane: a review, Chin. J. Catal. 32 (2011) 207-216.

[29] A. Dufour, A. Celzard, V. Fierro, F. Broust, C. Courson, A. Zoulalian, et al., Catalytic conversion of methane over a biomass char for hydrogen production: deactivation and regeneration by steam gasification, Appl. Catal. A: Gen. 490 (2015) 170-180.

[30] D.P. Serrano, J.A. Botas, R. Guil-Lopez, $\mathrm{H}_{2}$ production from methane pyrolysis over commercial carbon catalysts: kinetic and deactivation study, Int. J. Hydrogen Energy 34 (2009) 4488-4494.

[31] D. Sutton, B. Kelleher, J.R.H. Ross, Review of literature on catalysts for biomass gasification, Fuel Process. Technol. 73 (2001) 155-173.

[32] A. Nzihou, B. Stanmore, P. Sharrock, A review of catalysts for the gasification of biomass char, with some reference to coal, Energy 58 (2013) 305-317.

[33] Z. Min, P. Yimsiri, M. Asadullah, S. Zhang, C.-Z. Li, Catalytic reforming of tar during gasification. Part II. Char as a catalyst or as a catalyst support for tar reforming, Fuel 90 (2011) 2545-2552.

[34] Y.L. Zhang, W.G. Wu, S.H. Zhao, Y.F. Long, Y.H. Luo, Experimental study on pyrolysis tar removal over rice straw char and inner pore structure evolution of char, Fuel Process. Technol. 134 (2015) 333-344.

[35] S. Zhao, Y. Luo, Y. Zhang, Y. Long, Experimental investigation of the synergy effect of partial oxidation and bio-char on biomass tar reduction, J. Anal. Appl. Pyrolysis 112 (2015) 262-269.

[36] K. Zeng, D. Pham Minh, D. Gauthier, E. Weiss-Hortala, A. Nzihou, G. Flamant, The effect of temperature and heating rate on char properties obtained from solar pyrolysis of beech wood, Bioresour. Technol. 182 (2015) 114-119.

[37] T.H.C. Yeo, I.A.W. Tan, M.O. Abdullah, Development of adsorption air-conditioning technology using modified activated carbon - a review, Renewable Sustain. Energy Rev. 16 (2012) 3355-3363.

[38] T.-H. Le, P.J.J. Dumont, L. Orgéas, D. Favier, L. Salvo, E. Boller, X-ray phase contrast microtomography for the analysis of the fibrous microstructure of SMC composites, Composites: Part A 39 (2008) 91-103.

[39] S. Jeffery, M.B.J. Meinders, C.R. Stoof, T.M. Bezemer, T.F.J. van de Voorde, L. Mommer, et al., Biochar application does not improve the soil hydrological function of a sandy soil, Geoderma 251-252 (2015) 47-54.

[40] K. Jones, G. Ramakrishnan, M. Uchimiya, A. Orlov, New applications of X-ray tomography in pyrolysis of biomass: biochar imaging, Energy Fuels 29 (2015) 1628-1634.

[41] T. Pattanotai, H. Watanabe, K. Okazaki, Effects of particle aspect ratio on pyrolysis and gasification of anisotropic wood cylinder, Fuel 150 (2015) 162-168.

[42] J.M. Jones, M. Pourkashanian, C.D. Rena, A. Williams, Modelling the relationship of coal structure to char porosity, Fuel 78 (1999) 1737-1744.

[43] V. Fernandez-Alos, J.K. Watson, R. van der Wal, J.P. Mathews, Soot and char molecular representations generated directly from HRTEM lattice fringe images using Fringe3D, Combust. Flame 158 (2011) 1807-1813.

[44] W.J. Liu, H. Jiang, H.Q. Yu, Development of biochar-based functional materials: toward a sustainable platform carbon material, Chem. Rev. 115 (2015) $12251-12285$

[45] E. Mura, O. Debono, A. Villot, F. Paviet, Pyrolysis of biomass in a semi-industrial scale reactor: study of the fuel-nitrogen oxidation during combustion of volatiles, Biomass Bioenergy 59 (2013) 187-194.

[46] I. Abe, M. Hitomi, N. Ikuta, H. Tatsumoto, Y. Kera, Pore structural analysis of charcoals by mercury intrusion porosimetry, TANSO 172 (1996) 77-82.

[47] A. Mirone, E. Brun, E. Gouillart, P. Tafforeau, J. Kieffer, The PyHST2 hybrid distributed code for high speed tomographic reconstruction with iterative 
reconstruction and a priori knowledge capabilities, Nucl. Instrum. Methods Phys. Res., Sect. B 324 (2013) 41-48.

[48] D. Paganin, S.C. Mayo, T.E. Gureyev, P.R. Miller, S.W. Wilkins, Simultaneous phase and amplitude extraction from a single defocused image of a homogeneous object, J. Microsc. 206 (2002) 33-40

[49] A.X. Falcao, J. Stolfi, R. de Alencar Lotufo, The image foresting transform: theory, algorithms, and applications, Pattern Anal. Mach. Intell. 26 (2004) 19-29.

[50] E.J. Watts, Ultramicrotomy of carbon-graphite materials for transmission electron microscopy, Metallography 9 (1976) 43-49.

[51] P. Pré, G. Huchet, D. Jeulin, J.N. Rouzaud, M. Sennour, A. Thorel, A new approach to characterize the nanostructure of activated carbons from mathematical morphology applied to high resolution transmission electron microscopy images, Carbon 52 (2013) 239-258.

[52] P. Trtik, J. Dual, D. Keunecke, D. Mannes, P. Niemz, P. Stähli, et al., 3D imaging of microstructure of spruce wood, J. Struct. Biol. 159 (2007) 46-55.

[53] M. Asadullah, S. Zhang, Z. Min, P. Yimsiri, C.Z. Li, Effects of biomass char structure on its gasification reactivity, Bioresour. Technol. 101 (2010) 7935-7943.

[54] G.S. Szymański, Z. Karpiński, S. Biniak, A. Świątkowski, The effect of the gradual thermal decomposition of surface oxygen species on the chemical and catalytic properties of oxidized activated carbon, Carbon 40 (2002) 2627-2639.

[55] I.I. Salame, T.J. Bandosz, Surface chemistry of activated carbons: combining the results of temperature-Programmed desorption, boehm, and potentiometric titrations, J. Colloid Interface Sci. 240 (2001) 252-258.

[56] D.M. Keown, J.I. Hayashi, C.Z. Li, Drastic changes in biomass char structure and reactivity upon contact with steam, Fuel 87 (2008) 1127-1132.

[57] J. McDonald-Wharry, M. Manley-Harris, K. Pickering, Carbonisation of biomassderived chars and the thermal reduction of a graphene oxide sample studied using
Raman spectroscopy, Carbon 59 (2013) 383-405.

[58] M.I. Bird, P.L. Ascough, I.M. Young, C.V. Wood, A.C. Scott, X-ray microtomographic imaging of charcoal, J. Archaeolog. Sci. 35 (2008) 2698-2706.

[59] A. Sadezki, H. Muckenhuber, H. Grothe, R. Niessner, U. Pöschl, Raman microspectroscopy of soot and related carbonaceous materials: spectral analysis and structural information, Carbon 43 (2005) 1731-1742.

[60] A. Moilanen, H.J. Mühlen, Characterization of gasification reactivity of peat char in pressurized conditions: effect of product gas inhibition and inorganic material, Fuel 75 (1996) 1279-1285.

[61] P. Fu, W. Yi, X. Bai, Z. Li, S. Hu, J. Xiang, Effect of temperature on gas composition and char structural features of pyrolyzed agricultural residues, Bioresour. Technol. 10 (2011) 8211-8219.

[62] B. Manoj, A.G. Kunjomana, Study of stacking structure of amorphous carbon by Xray diffraction technique, Int. J. Electrochem. Sci. 7 (2012) 3127-3134.

[63] M.S. Hasan Khan Tushar, N. Mahinpey, A. Khan, H. Ibrahim, P. Kumar, R. Idem, Production, characterization and reactivity studies of chars produced by the isothermal pyrolysis of flax straw, Biomass Bioenergy 37 (2012) 97-105.

[64] K.N. Kudin, B. Ozbas, H.C. Schniepp, R.K. Prud'homme, I.A. Aksay, R. Car, Raman spectra of graphite oxide and functionalized graphene sheets, Nano Lett. 8 (2008) $36-41$.

[65] E. Cetin, B. Moghtaderi, R. Gupta, T.F. Wall, Influence of pyrolysis conditions on the structure and gasification reactivity of biomass chars, Fuel 83 (2004) 2139-2150.

[66] X. Li, J. Hayashi, C.Z. Li, FT-Raman spectroscopic study of the evolution of char structure during the pyrolysis of a Victorian brown coal, Fuel 85 (2006) 1700-1707.

[67] D.M. Keown, X. Li, J.I. Hayashi, C.Z. Li, Evolution of biomass char structure during oxidation in $\mathrm{O}_{2}$ as revealed with FT-Raman spectroscopy, Fuel Process. Technol. 89 (2008) 1429-1435. 